\title{
Health Care, Family, and Community Factors Associated with Mental, Behavioral, and Developmental Disorders in Early Childhood — United States, 2011-2012
}

\begin{abstract}
Rebecca H. Bitsko, $\mathrm{PhD}^{1}$; Joseph R. Holbrook, $\mathrm{PhD}^{1}$; Lara R. Robinson, $\mathrm{PhD}^{1}$; Jennifer W. Kaminski, $\mathrm{PhD}^{1}$; Reem $\mathrm{Ghandour}$, DrPH${ }^{2}$;
\end{abstract} Camille Smith, EdS ${ }^{3}$; Georgina Peacock, $\mathrm{MD}^{1}$

Sociodemographic, health care, family, and community attributes have been associated with increased risk for mental, behavioral, and developmental disorders (MBDDs) in children $(1,2)$. For example, poverty has been shown to have adverse effects on cognitive, socio-emotional, and physical development (1). A safe place to play is needed for gross motor development, and accessible health care is needed for preventive and illness health care (3). Positive parenting and quality preschool interventions have been shown to be associated with prosocial skills, better educational outcomes, and fewer health risk behaviors over time (2). Protective factors for MBDDs are often shared (4) and conditions often co-occur; therefore, CDC considered MBDDs together to facilitate the identification of factors that could inform collaborative, multidisciplinary prevention strategies. To identify specific factors associated with MBDDs among U.S. children aged 2-8 years, parent-reported data from the most recent (2011-2012) National Survey of Children's Health (NSCH) were analyzed. Factors associated with having any MBDD included inadequate insurance, lacking a medical home, fair or poor parental mental health, difficulties getting by on the family's income, employment difficulties because of child care issues, living in a neighborhood lacking support, living in a neighborhood lacking amenities (e.g., sidewalks, park, recreation center, and library), and living in a neighborhood in poor condition. In a multivariate analysis, fair or poor parental mental health and lacking a medical home were significantly associated with having an MBDD. There was significant variation in the prevalence of these and the other factors by state, suggesting that programs and policies might use collaborative efforts to focus on specific factors. Addressing identified factors might prevent the onset of MBDDs and improve outcomes among children who have one or more of these disorders.
NSCH is a cross-sectional, nationally representative, random-digit-dialed telephone survey that collects information about U.S. children aged $<18$ years. The survey includes indicators of child health and well-being, access to quality health care, family characteristics, and school and neighborhood environment.* Participating parents or guardians completed interviews about one randomly selected child $(\mathrm{N}=95,677)$ per household. The interview completion rates were $54.1 \%$

\footnotetext{
*http://www.cdc.gov/nchs/slaits/nsch.htm and ftp://ftp.cdc.gov/pub/Health_ Statistics/NCHS/slaits/nsch_2011_2012/01_Frequently_asked_questions/ NSCH_2011_2012_FAQs.pdf.
}

\section{INSIDE}

227 Evaluation of a National Call Center and a Local Alerts System for Detection of New Cases of Ebola Virus Disease — Guinea, 2014-2015

231 Update: Providing Quality Family Planning Services - Recommendations from CDC and the U.S. Office of Population Affairs, 2015

235 Vital Signs: Preventing Antibiotic-Resistant Infections in Hospitals — United States, 2014

242 Increase in Reported Prevalence of Microcephaly in Infants Born to Women Living in Areas with Confirmed Zika Virus Transmission During the First Trimester of Pregnancy - Brazil, 2015

248 Notes from the Field: Lymphocytic Choriomeningitis Virus Meningoencephalitis from a Household Rodent Infestation - Minnesota, 2015

251 QuickStats

Continuing Education examination available at http://www.cdc.gov/mmwr/cme/conted_info.html\#weekly.

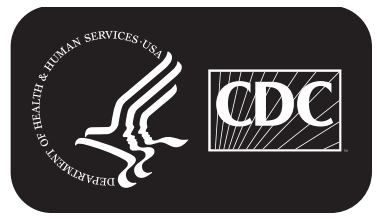

U.S. Department of Health and Human Services Centers for Disease Control and Prevention 
and $41.2 \%$ for landline and cell phone samples, respectively; the overall response rate was $23.0 \% .^{\dagger}$ Data were weighted to account for unequal probability of selection of each household and child and for nonresponse. Weighted estimates reflect the population of noninstitutionalized children in the United States and within each state.

Parents were asked, "Has a doctor or other health care provider ever told you that [child] had [specified disorder]?” A child was considered to have an MBDD if the parent or guardian reported any of the following: attention-deficit/ hyperactivity disorder (ADHD), depression, anxiety problems, behavioral or conduct problems such as oppositional defiant disorder or conduct disorder, Tourette syndrome, autism spectrum disorder, learning disability, intellectual disability, developmental delay, or speech or other language problems.

Analyses were restricted to the 35,121 U.S. children aged 2-8 years (defined by Healthy People 2020 as "early childhood") with data for sex and each disorder. Weighted prevalence estimates of having any MBDD, and the associations with sociodemographic, health care, family, and community factors were calculated using statistical software to account for the complex sampling. Given previously documented

\footnotetext{
$\dagger$ The response rate is the percentage of households that completed interviews among all eligible households, including those that were not successfully contacted. The cooperation rate is the percentage of households that completed interviews among all eligible households that were contacted. NSCH attempts to minimize nonresponse bias by incorporating nonresponse adjustments in the development of the sampling weights.
}

associations between health care, family, and community factors, an exploratory regression model was also fit to determine which of the health care, family, or community factors that were independently associated with any MBDD remained significant after adjusting for the others. Sociodemographic factors were not included in the model.

Overall, among U.S. children aged $2-8$ years, $15.4 \%$ had at least one diagnosed MBDD, by parent report (Table 1). Sociodemographic factors associated with report of having an MBDD included male sex, older age (aged 4-5 or 6-8 years compared with 2-3 years), being non-Hispanic white, and living in a household with a higher poverty level (i.e., $<200 \%$ of federal poverty level) or where English was the primary language spoken.

Specific factors most strongly associated with MBDDs in early childhood were fair or poor parental mental health, difficulty getting by on the family's income, child care problems (among parents of children aged 2-3 years), and lacking a medical home. Factors with the highest prevalence among children with MBDDs included lacking a medical home, living in a neighborhood lacking amenities, difficulty getting by on family income, and living in a neighborhood in poor condition. When adjusted for the other significant health care, family, and community factors, an exploratory multivariate model showed that only lacking a medical home and fair or poor parental mental health remained significantly associated with having an MBDD (Table 2).

The $M M W R$ series of publications is published by the Center for Surveillance, Epidemiology, and Laboratory Services, Centers for Disease Control and Prevention (CDC), U.S. Department of Health and Human Services, Atlanta, GA 30329-4027.

Suggested citation: [Author names; first three, then et al., if more than six.] [Report title]. MMWR Morb Mortal Wkly Rep 2016;65:[inclusive page numbers].

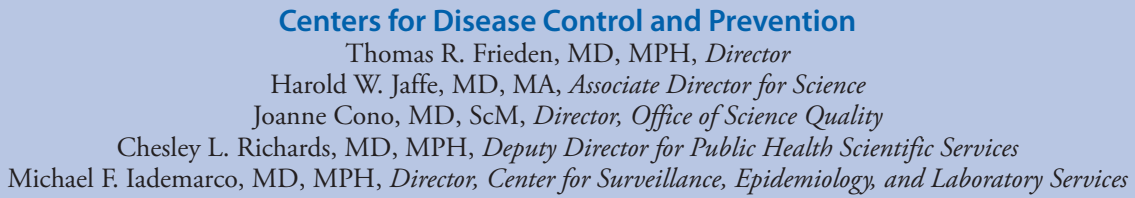

MMWR Editorial and Production Staff (Weekly)

Sonja A. Rasmussen, MD, MS, Editor-in-Chief

Charlotte K. Kent, PhD, MPH, Executive Editor Jacqueline Gindler, MD, Editor

Teresa F. Rutledge, Managing Editor

Douglas W. Weatherwax, Lead Technical Writer-Editor

Soumya Dunworth, PhD, Teresa M. Hood, MS, Technical Writer-Editors

Timothy F. Jones, MD, Chairman

Matthew L. Boulton, MD, MPH

Virginia A. Caine, MD

Katherine Lyon Daniel, PhD

Jonathan E. Fielding, MD, MPH, MBA

David W. Fleming, MD

Martha F. Boyd, Lead Visual Information Specialist

Maureen A. Leahy, Julia C. Martinroe,

Stephen R. Spriggs, Moua Yang, Tong Yang, Visual Information Specialists

Quang M. Doan, MBA, Phyllis H. King, Terraye M. Starr, Information Technology Specialists

MMWR Editorial Board

William E. Halperin, MD, DrPH, MPH

King K. Holmes, MD, PhD

Robin Ikeda, MD, MPH

Rima F. Khabbaz, MD

Phyllis Meadows, PhD, MSN, RN

Jewel Mullen, MD, MPH, MPA
Jeff Niederdeppe, $\mathrm{PhD}$

Patricia Quinlisk, MD, MPH

Patrick L. Remington, MD, MPH Carlos Roig, MS, MA

William L. Roper, MD, MPH

William Schaffner, MD 
TABLE 1. Prevalence of ever having any mental, behavioral, or developmental disorder (MBDD) ${ }^{*}$ by parent report, among children aged 2-8 years, by selected characteristics - National Survey of Children's Health, United States, 2011-2012

\begin{tabular}{|c|c|c|c|}
\hline Characteristic & $\begin{array}{c}\text { Any MBDD } \\
\text { prevalence }(95 \% \mathrm{Cl})\end{array}$ & $\begin{array}{c}\text { Prevalence ratio } \\
(95 \% \mathrm{Cl})\end{array}$ & $p$ value \\
\hline Overall & $15.4(14.6-16.2)$ & - & - \\
\hline $\begin{array}{l}\text { Sex } \\
\text { Male } \\
\text { Female }\end{array}$ & $\begin{array}{l}19.5(18.3-20.8) \\
11.0(10.1-12.0)\end{array}$ & $\begin{array}{r}1.8(1.6-2.0) \\
\text { Referent }\end{array}$ & $\begin{array}{r}<0.001 \\
-\end{array}$ \\
\hline $\begin{array}{l}\text { Age group (yrs) } \\
2-3 \\
4-5 \\
6-8\end{array}$ & $\begin{array}{r}9.2(8.1-10.5) \\
14.6(13.2-16.1) \\
19.7(18.4-21.0)\end{array}$ & $\begin{array}{r}\text { Referent } \\
1.6(1.3-1.9) \\
2.1(1.8-2.5)\end{array}$ & $\begin{array}{r}- \\
<0.001 \\
<0.001\end{array}$ \\
\hline $\begin{array}{l}\text { Race/Ethnicity } \\
\text { White, non-Hispanic } \\
\text { Black, non-Hispanic } \\
\text { Hispanic } \\
\text { Other, non-Hispanic }{ }^{\dagger}\end{array}$ & $\begin{array}{l}16.8(15.9-17.9) \\
15.0(12.9-17.4) \\
13.5(11.7-15.6) \\
14.1(12.1-16.4)\end{array}$ & $\begin{array}{r}\text { Referent } \\
0.9(0.8-1.0) \\
0.8(0.7-0.9) \\
0.8(0.7-1.0)\end{array}$ & $\begin{array}{r}- \\
0.158 \\
0.006 \\
0.030\end{array}$ \\
\hline $\begin{array}{l}\text { Federal poverty level } \\
<100 \% \\
100 \%-199 \% \\
200 \%-399 \% \\
\geq 400 \%\end{array}$ & $\begin{array}{l}18.7(16.8-20.8) \\
16.4(14.7-18.2) \\
14.2(12.8-15.8) \\
12.5(11.3-13.9)\end{array}$ & $\begin{array}{r}1.5(1.3-1.7) \\
1.3(1.1-1.5) \\
1.1(1.0-1.3) \\
\quad \text { Referent }\end{array}$ & $\begin{array}{r}<0.001 \\
<0.001 \\
0.081 \\
-\end{array}$ \\
\hline $\begin{array}{l}\text { Highest education leve } \\
\text { Less than high school } \\
\text { High school graduate } \\
\text { More than high school }\end{array}$ & $\begin{array}{l}\text { household" } \\
14.0(12.0-16.2) \\
16.3(14.8-17.8) \\
15.3(14.3-16.5)\end{array}$ & $\begin{array}{r}0.9(0.8-1.1) \\
1.1(0.9-1.2) \\
\text { Referent }\end{array}$ & $\begin{array}{r}0.267 \\
0.331 \\
-\end{array}$ \\
\hline $\begin{array}{l}\text { Primary household lan } \\
\text { English } \\
\text { Any other language }\end{array}$ & $\begin{array}{l}\text { age } \\
\quad 16.3(15.5-17.2) \\
10.9(9.0-13.2)\end{array}$ & $\begin{array}{r}1.5(1.2-1.8) \\
\text { Referent }\end{array}$ & $\begin{array}{r}<0.001 \\
-\end{array}$ \\
\hline
\end{tabular}

Abbreviation: $\mathrm{Cl}=$ confidence interval.

* Including parent report of whether they were ever told by a health care professional that the child had attention-deficit/hyperactivity disorder (ADHD), depression, anxiety problems, behavioral or conduct problems such as oppositional defiant disorder or conduct disorder, Tourette syndrome, autism spectrum disorder, learning disability, intellectual disability, developmental delay, or speech or other language problems.

+ Includes American Indian/Alaska Native, Native Hawaiian or Other Pacific Islander, and Asian.

$\S$ Federal poverty level is based on family income and family size and composition using federal poverty thresholds that are updated annually by the U.S. Census Bureau using the change in the average annual consumer price index for all urban consumers. Imputed income was used for $9.3 \%$ of children aged 2-8 years without reported household income.

" Based on the education of adult parents or respondents.

The prevalence of MBDDs and health care, family, and community factors among U.S. children aged $2-8$ years varied by state (supplemental table at http://stacks.cdc.gov/view/ cdc/38108). Prevalence of having any disorder varied from $10.6 \%$ in California to $21.5 \%$ in Arkansas and Kentucky. More than $90 \%$ of children received preventive care (i.e., parent or guardian reported that in the past 12 months, the child saw a health care provider for preventive medical care such as a physical exam or well-child checkup at least once) in each state.

Among health care factors, inadequate insurance was highest in South Carolina (26.5\%), and lacking a medical home was highest in Arizona (52.2\%); Vermont had the lowest prevalence of both inadequate insurance (14.7\%) and lacking a medical home (27\%).
The prevalences of difficulty getting by on the family's income and child care problems were both highest in Arizona (34.9\% and $21.8 \%$, respectively); income difficulties were lowest in North Dakota (18.5\%), whereas child care problems were lowest in Nevada $\left(2.6 \%{ }^{\S}\right)$. Fair or poor parental mental health prevalence was highest in the District of Columbia (19.1\%) and lowest in Kansas (6.9\%).

The District of Columbia had the highest prevalence of living in a neighborhood in poor condition $(46.2 \%)$ but the lowest prevalence of living in a neighborhood without all of the reported amenities (26.7\%); the lowest prevalence of living in a neighborhood in poor condition was $20 \%$ in Maryland, whereas the highest prevalence of living in a neighborhood without all of the reported amenities was $67.5 \%$ in Mississippi (67.5\%). Finally, reported prevalence of lack of neighborhood support was highest in Arizona (32.9\%) and lowest in North Dakota (7.9\%).

\section{Discussion}

Mental, behavioral, and developmental disorders identified in childhood often persist into adulthood and are associated with increased risk for poorer school outcomes and employment opportunities, other adverse health conditions, earlier mortality, and considerable costs for persons with the disorders, their families, and society (2). Children are more likely to outgrow speech or language problems or certain developmental delays than other MBDDs, particularly if they receive early intervention. In other disorders such as Tourette syndrome, some children might outgrow the condition by late adolescence but remain at increased risk for other disorders that are more likely to persist, including ADHD and obsessive-compulsive disorder. MBDDs can substantially affect health care, families, and communities. Children with MBDDs often require more health and therapy services than children without MBDDs. Families might face stress associated with the disorder itself or financial stress associated with treatment of the disorder. Communities might need to provide additional services and support for both children and families and might face lower productivity if the parent or guardian is unable to work (2). Thus, efforts to prevent the onset of MBDDs and to improve their identification and treatment in early childhood might improve health and well-being throughout the lifespan, with the potential to translate into cost savings and overall population health improvements (2).

The data in this report included a number of sociodemographic factors associated with MBDDs, including poverty and living in a primarily English-speaking household. Household

\footnotetext{
${ }^{\mathfrak{S}}$ Relative standard error for Nevada $=38 \%$; this estimate should be interpreted with caution.
} 
TABLE 2. Prevalence of ever having any mental, behavioral, or developmental disorder (MBDD) ${ }^{*}$ by parent report, among children aged 2-8 years, by health care, family, and community factors - National Survey of Children's Health, United States, 2011-2012

\begin{tabular}{|c|c|c|c|c|c|c|}
\hline Type of factor & $\begin{array}{l}\text { Any MBDD } \\
\%\left(95 \% \mathrm{CI}^{\dagger}\right)\end{array}$ & $\begin{array}{l}\text { No MBDD } \\
\%(95 \% \mathrm{Cl})\end{array}$ & $\begin{array}{c}\text { Any MBDD/ } \\
\text { No MBDD } \\
\text { prevalence ratio } \\
(95 \% \mathrm{Cl})\end{array}$ & p value & $\begin{array}{l}\text { Any MBDD/ } \\
\text { No MBDD adjusted } \\
\text { prevalence ratio }{ }^{\dagger} \\
(95 \% \mathrm{Cl})\end{array}$ & $p$ value \\
\hline \multicolumn{7}{|l|}{ Health care } \\
\hline Inadequate insurance for optimal health ${ }^{\S}$ & $26.3(24.0-28.8)$ & $20.4(19.3-21.4)$ & $1.3(1.2-1.4)$ & $<0.001$ & $1.3(0.9-2.1)$ & 0.168 \\
\hline No preventive medical care, last 12 months & $3.4(2.6-4.4)$ & $3.1(2.7-3.6)$ & $1.1(0.8-1.4)$ & 0.628 & Not included & - \\
\hline Lacks a medical home** & $56.8(54.1-59.5)$ & $41.9(40.6-43.2)$ & $1.4(1.3-1.4)$ & $<0.001$ & $2.1(1.5-3.1)$ & $<0.001$ \\
\hline \multicolumn{7}{|l|}{ Family } \\
\hline Fair or poor maternal mental health ${ }^{\dagger \dagger}$ & $12.7(10.9-14.7)$ & $6.7(6.0-7.6)$ & $1.9(1.6-2.3)$ & $<0.001$ & Not included & - \\
\hline Fair or poor paternal mental health ${ }^{\dagger \dagger}$ & $7.4(5.9-9.1)$ & $3.8(3.3-4.5)$ & $1.9(1.5-2.5)$ & $<0.001$ & Not included & - \\
\hline At least one parent with fair or poor mental health ${ }^{\dagger \dagger}$ & $19.6(17.2-22.3)$ & $9.9(9.0-10.9)$ & $2.0(1.7-2.3)$ & $<0.001$ & $1.8(1.1-2.9)$ & 0.019 \\
\hline Difficult to get by on family's income ${ }^{\S \S}$ & $35.5(32.8-38.3)$ & $24.0(22.9-25.2)$ & $1.5(1.4-1.6)$ & $<0.001$ & $1.1(0.7-1.6)$ & 0.760 \\
\hline Parent lacks emotional support & $11.8(10.2-13.7)$ & $11.3(10.4-12.3)$ & $1.0(0.9-1.2)$ & 0.616 & Not included & - \\
\hline Child care problems (children aged $2-3$ years only) ${ }^{* * *}$ & $19.5(14.9-25.3)$ & $12.9(11.4-14.5)$ & $1.5(1.1-2.0)$ & 0.007 & Not included & - \\
\hline \multicolumn{7}{|l|}{ Community } \\
\hline Neighborhood without amenities ${ }^{\dagger \dagger \dagger}$ & $45.5(42.6-48.3)$ & $42.2(40.9-43.5)$ & $1.1(1.0-1.2)$ & 0.040 & $1.0(0.7-1.4)$ & 0.889 \\
\hline Neighborhood in poor condition $§ \S \S$ & $34.5(31.8-37.2)$ & $27.6(26.4-28.7)$ & $1.3(1.1-1.4)$ & $<0.001$ & $1.1(0.8-1.7)$ & 0.560 \\
\hline Lack of support in neighborhood & $24.3(22.1-26.8)$ & $18.5(17.5-19.6)$ & $1.3(1.2-1.5)$ & $<0.001$ & $1.3(0.9-1.9)$ & 0.223 \\
\hline Neighborhood perceived to lack safety**** & $15.5(13.7-17.5)$ & $14.5(13.5-15.5)$ & $1.1(0.9-1.2)$ & 0.339 & Not included & - \\
\hline
\end{tabular}

Abbreviation: $\mathrm{Cl}=$ confidence interval.

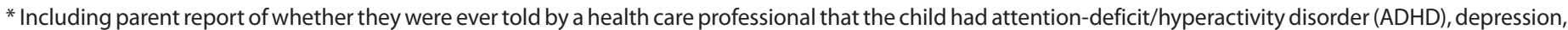

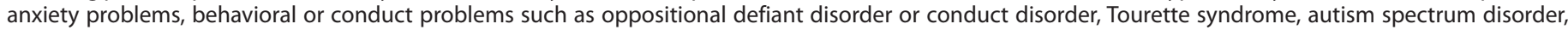
learning disability, intellectual disability, developmental delay, or speech or other language problems.

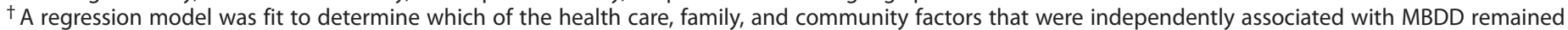

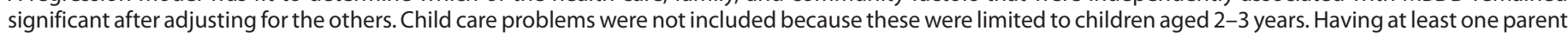
with fair or poor mental health was included in the model rather than individual paternal and maternal mental health indicators.

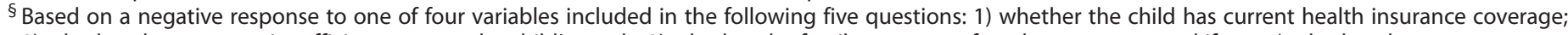

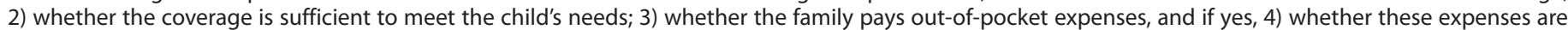
usually or always reasonable; and 5) whether insurance allows the child to see needed health care providers.

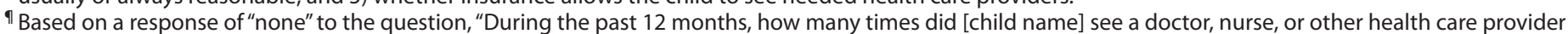
for preventive medical care such as a physical exam or well-child checkup?"

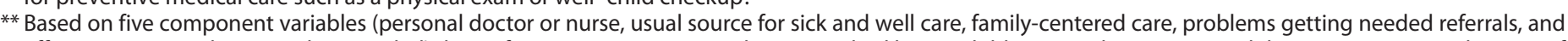

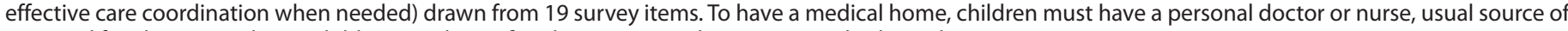
care, and family-centered care; children needing referrals or care coordination must also have those criteria met.

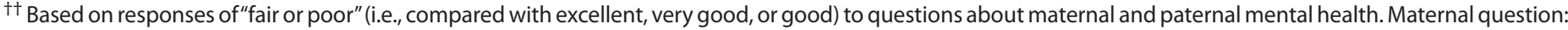

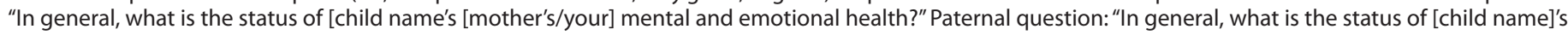
[father's/your] mental and emotional health?"

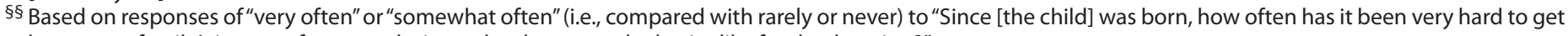
by on your family's income, for example, it was hard to cover the basics like food or housing?"

"ी Based on responses of "no" to "Is there someone that you can turn to for day-to-day emotional help with [parenthood/raising children]?"

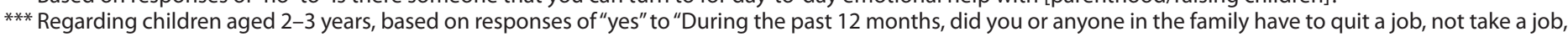
or greatly change your job because of problems with child care for [the child]?"

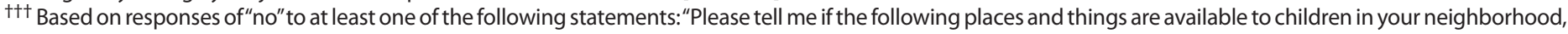

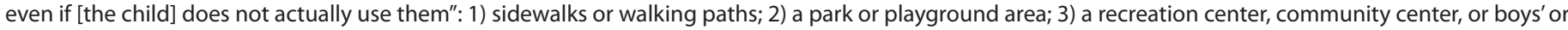
girls' club; 4) a library or bookmobile.

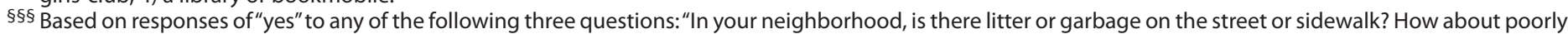
kept or rundown housing? How about vandalism such as broken windows or graffiti?"

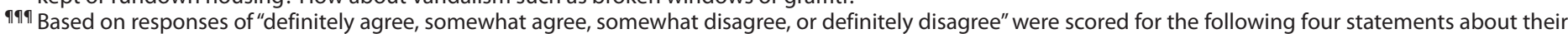

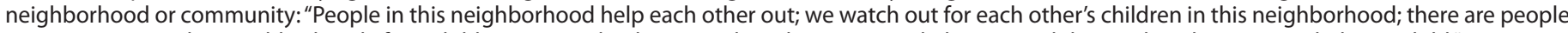

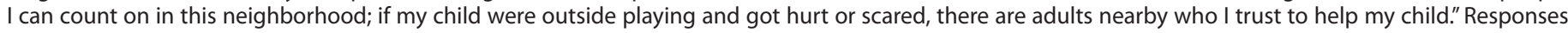
were scored 1-4 and an average score was calculated; averages less than 2.25 indicated a "lack of support."

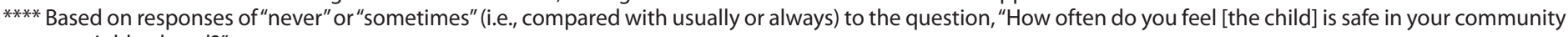
or neighborhood?"

language might be reflective of increased access to health care (and thus increased likelihood of being diagnosed) or the level of acculturation, a factor that has been associated with risk behaviors and poorer health outcomes in some domains (5). The identified health care, family, and community factors associated with child MBDDs in this report have each previously been documented to be associated with poverty $(\sigma)$. Each significant factor might reflect the effect of insufficient parental and community resources to support optimal child development and might contribute to chronic stress. Chronic stress in early childhood can impact lifelong health. A chronically activated physiologic stress response impacts the sympathetic nervous system, metabolism, and the brain, resulting in increased risk for high blood pressure, obesity, inflammatory diseases, and mental and behavioral disorders (1). The prevalences of both poverty and MBDDs have been increasing among U.S. 


\section{Summary}

What is already known about this topic?

Sociodemographic factors and environmental influences in early childhood have been demonstrated to have significant impact on development, mental health, and overall health throughout the lifespan.

What is added by this report?

This report provides recent national data documenting significant associations of early childhood mental, behavioral, and developmental disorders (MBDDs) with sociodemographic, health care, family, and community factors. There was substantial variation in state estimates of these factors and early childhood MBDDs. The factors most strongly associated with MBDDs were fair or poor parental mental health, difficulty getting by on the family's income, child care problems (among parents of children aged 2-3 years), and lacking a medical home.

What are the implications for public health practice?

These data support the Institute of Medicine recommendation that resources directed toward improving health care and supporting families and communities are needed to promote healthy development among all young children. Collaborative, multidisciplinary strategies including public health and pediatric clinical partners might have the greatest impact given the broad types of factors associated with early childhood MBDDs and the large number of agencies working to support optimal child development.

children, 5 underscoring the need for public health strategies to prevent and treat MBDDs (7).

The factors most strongly associated with MBDDs in early childhood were lacking a medical home, fair or poor parental mental health, and difficulty getting by on the family's income. These and the other factors varied widely by state and might inform state-level decisions regarding allocation of resources to improve early childhood health at the population level. Strategies that address socioeconomic (e.g., poverty) and community (e.g., neighborhood condition) factors form the foundation of the health impact pyramid framework where interventions have the greatest public health impact (8), including demonstrated impacts into adulthood, and are likely to be cost-effective $(2,9,10)$. Further analyses are needed to identify which factors might be the most effective targets to promote children's health.

Because a large percentage of children were reported to receive preventive care, pediatric clinical settings might be one venue for identifying and possibly delivering services to children and families in need. For example, the American Academy of Pediatrics has published policy statements on screening for postpartum depression (e.g., one way to address poor maternal mental health), the medical home, recognizing

\footnotetext{
'http://nccp.org/publications/pub_1099.html.
}

social determinants of health, and partnering with public health to address child health from a population perspective (3). Increased awareness of the association of these factors with MBDDs by agencies serving children, (e.g., health departments, schools, and community organizations) might improve referrals and stimulate partnerships to address early childhood health within established community settings (3).

The findings in this report are subject to at least five limitations. First, the presence of MBDDs was based on parent report and might be subject to recall error or bias. Second, children with undiagnosed disorders were not included, and therefore, state estimates of these disorders might vary both by presence of disorders and likelihood of identification. Similarly, state data on health care, family, and community factors might be influenced by prevalence of MBDDs. Third, the cross-sectional nature of the data and reliance on parent report prevented drawing conclusions about the direction of the associations or about causality. Fourth, although the data were weighted for nonresponse, bias related to nonresponse might remain given the low response rate. Finally, a wide range of disorders were included and might be differentially related to health care, family, and community factors, and also likely vary in the extent to which they can be prevented.

These data support the Institute of Medicine recommendation that resources directed toward improving health care and supporting families and communities are needed to prevent mental, emotional, and behavioral disorders, and promote healthy development among all young children (2). Such investments would require substantial collaboration across public health, pediatric, and other agencies responsible for providing services to children, but could yield widespread benefits for early childhood and lifelong health (8).

\footnotetext{
${ }^{1}$ Division of Human Development and Disability, National Center on Birth Defects and Developmental Disabilities, CDC; ${ }^{2}$ Office of Epidemiology and Research, Maternal and Child Health Bureau, Health Resources and Services Administration; ${ }^{3}$ Division of Congenital and Developmental Disorders, National Center on Birth Defects and Developmental Disabilities, CDC.

Corresponding author: Rebecca Bitsko, dvk2@cdc.gov, 404-498-3556.
}

\section{References}

1. Evans GW, Kim P. Childhood poverty, chronic stress, self-regulation, and coping. Child Dev Perspect 2013;7:43-8. http://dx.doi.org/10.1111/ cdep. 12013

2. National Research Council and Institute of Medicine. Preventing mental, emotional, and behavioral disorders among young people: progress and possibilities. Washington, DC: The National Academic Press; 2009.

3. Council on Community Pediatrics. Community pediatrics: navigating the intersection of medicine, public health, and social determinants of children's health. Pediatrics 2013;131:623-8. http://dx.doi.org/10.1542/ peds.2012-3933

4. Durlak JA. Common risk and protective factors in successful prevention programs. Am J Orthopsychiatry 1998;68:512-20. http://dx.doi. org/10.1037/h0080360 
5. Abraído-Lanza AF, Armbrister AN, Flórez KR, Aguirre AN. Toward a theory-driven model of acculturation in public health research. Am J Public Health 2006;96:1342-6. http://dx.doi.org/10.2105/ AJPH.2005.064980

6. Bradley RH, Corwyn RF. Socioeconomic status and child development. Annu Rev Psychol 2002;53:371-99. http://dx.doi.org/10.1146/annurev. psych.53.100901.135233

7. Houtrow AJ, Larson K, Olson LM, Newacheck PW, Halfon N. Changing trends of childhood disability, 2001-2011. Pediatrics 2014;134:530-8. http://dx.doi.org/10.1542/peds.2014-0594
8. Frieden TR. A framework for public health action: the health impact pyramid. Am J Public Health 2010;100:590-5. http://dx.doi. org/10.2105/AJPH.2009.185652

9. Williams DR, Costa MV, Odunlami AO, Mohammed SA. Moving upstream: how interventions that address the social determinants of health can improve health and reduce disparities. J Public Health Manag Pract 2008;14(Suppl):S8-17. http://dx.doi.org/10.1097/01. PHH.0000338382.36695.42

10. Heckman JJ. Skill formation and the economics of investing in disadvantaged children. Science 2006;312:1900-2. http://dx.doi. org/10.1126/science. 1128898 